\title{
REVISÃO ESTRATIGRÁFICA DOS DEPÓSITOS MIOCÊNICOS AFLORANTES NA REGIÃO DO ALTO DE OLIVENÇA, LITORAL SUL DO ESTADO DA BAHIA, BRASIL
}

\author{
LINA LILIANA OSORIO SANABRIA, EGBERTO PEREIRA \& LUZIA ANTONIOLI \\ FGEL/UERJ, Rua São Francisco Xavier, 524, 20-550013, Rio de Janeiro, RJ, Brasil. \\ linalili63@gmail.com,egberto@uerj.br,luantonioli@ig.com.br
}

\begin{abstract}
STRATIGRAPHIC REVISION OF MIOCENE DEPOSITS OUTCROPPING IN THE ALTO OLIVENÇA REGION, SOUTH COAST BAHIA STATE, BRAZIL. The outcropping deposits on the southern coast of the Bahia State have been commonly described as predominantly continental and lithostratigraphically to the Barreiras Formation. Furthermore, despite its regional approach, this paper presents geological data suggesting a marine influence during deposition of these sediments. Faciological and palynological characterization, as well as geochemical studies were integrated to stratigraphically characterize the black shales exposed in the coastal region between Ilhéus and Una, Bahia State. Based on faciological interpretation, it was possible to generate a model of facies association consisting predominantly of subtidal/intertidal deposits. The shallow marine environment is suggested by the sedimentary structures attributed to tidal processes as well as by the presence of marine palynomorphs (microfaraminifers test linings) along with woody organic material. The presence of the species Lanagiopollis crassa, Multiareolites formosus, Deltoidospora adriennis, Retimonocolpites cf. R. maximus, and Psilatricolpites divisus suggests that the outcropping shales were deposited in the Miocene, within a progressive shallowing trend, in the context of a highstand system tract, which would have developed thick shallow water shale packages interspersed with tidal sand bars, in a tide-dominated estuarine system.
\end{abstract}

Key words: marine palynomorph, stratigraphy, Barreiras Formation, Rio Doce Formation, biomarkers.

RESUMO - Os depósitos aflorantes no litoral sul do Estado da Bahia têm sido comumente descritos como depósitos predominantemente continentais associados à Formação Barreiras. Embora ainda de caráter regional, o presente trabalho apresenta dados que sugerem uma influência marinha durante a deposição destes sedimentos. Análises faciológica, palinológica e geoquímica foram integradas com o objetivo de caracterizar estratigraficamente os sedimentos aflorantes ao longo da faixa litorânea entre as cidades de Ilhéus e Una no Estado da Bahia. Com base nas informações faciológicas foi possível reconhecer uma associação de fácies indicativa de depósitos de inframaré/intermaré em contexto costeiro. O ambiente deposicional é sugerido pelas estruturas sedimentares atribuídas aos processos de maré, bem como pela presença de palinomorfos marinhos (microforaminíferos) junto com material orgânico lenhoso. A presença das espécies: Lanagiopollis crassa, Multiareolites formosus, Deltoidospora adriennis, Retimonocolpites cf. R. maximus, e Psilatricolpites divisus, sugerem que os folhelhos aflorantes foram depositados no Mioceno. Esta deposição ocorreu dentro de uma progressiva tendência de raseamento, no contexto de um trato de sistema de mar alto, onde teriam sido desenvolvidos espessos pacotes de sedimentos finos de água rasa, intercalados com barras arenosas num sistema estuarino.

Palavras-chave: palinomorfos marinhos, estratigrafia, Formação Barreiras, Formação Rio Doce, biomarcadores.

\section{INTRODUÇÃO}

Na Região Sul do Estado da Bahia, na Praia de Cururupe entre a cidade de Ilhéus até o Alto de Olivença, ocorrem afloramentos de folhelhos negros e arenitos, cujas feições despertaram interesse, uma vez que são comumente descritos na literatura como depósitos recentes ou pertencentes à Formação Barreiras, de idade pliocena a pleistocena (Gontijo et al., 2007).

Os depósitos da Formação Barreiras bordejam a zona costeira brasileira desde o Estado do Amapá até o Estado do Rio de Janeiro, recobrindo depósitos sedimentares mesozoicos de diversas bacias costeiras (Arai, 2006). De maneira geral, os estudos realizados para esta formação são de caráter regional. Recentemente, Bezerra et al. (2006) promoveram as primeiras discussões sobre diversos aspetos estratigráficos e genéticos para esses depósitos, assim como estudos mais específicos de ambientes deposicionais e processos sedimentares da Formação Barreiras para locais específicos no litoral brasileiro. Entretanto, diversos trabalhos apresentam novas discussões a partir das variações eustáticas durante o Mioceno. A utilização de datações palinológicas (Leite, 1997; Leite et al., 1997; Leite, 2004; Arai \& Novais, 2006), e correlações estratigráficas (Shimabukuro \& Arai, 1999, 2000 e 2001) sugeriram um ambiente transicional até marinho raso, principalmente, na região norte e nordeste do Brasil. 
Apesar da ampla distribuição geográfica, os detalhamentos destes depósitos na região sul do Estado da Bahia são associados a modelos principalmente continentais, segundo Lima et al. (2006). Os referidos autores, a partir do trabalho de campo entre as cidades de Porto Seguro e Prado, litoral sul da Bahia, descreveram depósitos litorâneos como resultantes de fluxos gravitacionais correspondentes à Formação Barreiras. Com base em análises faciológicas e detalhado estudo tectônico, definiram fácies principalmente fluviais, de leques aluviais, canais entrelaçados com lagos efêmeros que evoluem até canais bem desenvolvidos, que posteriormente foram afetados pela tectônica recente. Rossetti \& Dominguez (2011) sustentam evidências marinhas durante a deposição desta unidade no litoral norte do Estado da Bahia. Os autores descreveram afloramentos, a partir da diversidade de associações de fácies, que incluíram análises icnológicas, associadas a sistemas deposicionais que gradam desde fluvial até costeiro, relacionados à atuação de correntes de maré em ambiente estuarino. Arai (2006) sugeriu a denominação da Formação Barreiras como "Grupo" subdividido em duas unidades, mostrando evidências de caráter marinho na porção mais basal, denominada informalmente "Barreiras inferior", a qual teria sido depositada durante a subida eustática do nível de mar, no Mioceno (Arai \& Novais, 2006), sendo limitada no topo por uma discordância de idade tortoniana. A este conjunto, segue-se um pacote predominantemente continental definido informalmente como "Barreiras superior", de idade pleistocena inferior (Vilas Bôas et al., 2001; Arai, 2006).

$\mathrm{Na}$ literatura geológica publicada há carência de dados faciológicos detalhados que permitam completo entendimento dos processos e ambientes de sedimentação da Formação Barreiras. Nesse sentido, o presente trabalho objetiva fazer a descrição detalhada dos sedimentos registrados em superfície, e em especial dos folhelhos, por meio da identificação da matéria orgânica presente nesses sedimentos finos, com auxilio de análises geoquímicas (teores de carbono orgânico total e biomarcadores) e estudos palinológicos, uma vez que a determinação da idade dos depósitos e as condições paleoambientais da deposição permitirão correlação com os demais depósitos representativos para este intervalo de tempo.

Vale a pena ressaltar que os registros palinológicos relativos à Formação Barreiras são escassos e descontínuos, o que limita as reconstituições paleoambientais mais precisas, com assinaturas cronológicas bastante abrangentes, pela natureza afossilífera desta unidade. No Estado da Bahia, na região de Comandatuba, existe um único estudo palinológico (Arai \& Novais, 2006) que compreende idade miocena. Porém, são poucas as publicações existentes que abarquem todo o intervalo deposicional definido para a Formação Barreiras.

\section{MATERIAL E MÉTODOS}

Tendo como foco a realização da descrição estratigráfica dos folhelhos pretos observados paralelamente ao litoral entre as cidades de Ilhéus e Una, o mapa geológico da área de estudo é apresentado na Figura 1, o qual inclui a localização geográfica de sete pontos estudados na região. Nas áreas de ocorrência dos depósitos de interesse deste estudo foram selecionados quatro afloramentos representativos para a elaboração de seções estratigráficas (Pontos 02, 05, 06 e 07). $\mathrm{O}$ trabalho foi centrado na definição das principais fácies com suas propriedades litológicas e estruturas sedimentares, determinação da natureza dos limites entre os estratos. Finalmente, a amostragem sistemática dos folhelhos foi realizada em três afloramentos (Pontos 05, 06 e 07). Um total de dez amostras representativas dos intervalos de interesse foi encaminhado para análises geoquímicas estando estas amostras representadas com o símbolo "LALM" nos perfis estratigráficos.

As análises em rocha total de carbono orgânico total (COT), enxofre total (S), resíduo insolúvel (RI), pirólise Rock Eval e biomarcadores foram realizadas no Laboratório de Estratigrafia Química e Geoquímica Orgânica (LGQM) da Faculdade de Geologia da UERJ. O resultado do resíduo insolúvel foi obtido por processo de acidificação, para eliminação de carbonatos presentes na rocha. Utilizou-se o analisador LECO SC-634, para a determinação do carbono orgânico total e enxofre total, nas amostras previamente acidificadas. A partir desses resultados, foram encaminhadas cinco amostras, para análises de pirólise e biomarcadores.

As análises de pirólise foram executadas no equipamento de marca Vinci, modelo Rock-Eval VI, segundo a metodologia proposta por Espitalié et al. (1977). Para o procedimento analítico de biomarcadores, foi realizada a extração solúvel da matéria orgânica das amostras em sistema tipo Soxhlet, com reagente diclorometano como solvente extrator durante 48 h. O betume orgânico obtido na etapa anterior foi concentrado e fracionado por cromatografia líquida, conforme o procedimento descrito por Obermajer et al. (1998), cujo objetivo é a separação em duas frações: hidrocarbonetos saturados e aromáticos. A fração de compostos orgânicos saturados foi injetada no cromatógrafo a gás $(\mathbf{G C} / \mathbf{M S})$ da marca Agilent modelo 6890, equipado com injetor automático, acoplado a um detector de massas da mesma marca, modelo 5973 Network.

A amostragem palinológica incidiu principalmente nas fácies de folhelhos com teores de carbono orgânico total superior a $4 \%$ correspondente ao ponto 06 . O tratamento empregado para recuperação de palinomorfos seguiu o protocolo de Uesugui (1979), que se constituiu da desagregação física e dissolução dos componentes minerais, remoção de carbonato por adição de ácido clorídrico (20\%) e dissolução dos silicatos por imersão em ácido fluorídrico concentrado (70\%), seguido posteriormente pela concentração de palinomorfos conforme os procedimentos estabelecidos no Laboratório de Palinomacerais da Faculdade de Geologia da Universidade Estadual do Rio de Janeiro (FGEL-UERJ). As lâminas de palinomorfos foram examinadas em detalhe a partir de imagens capturadas usando uma câmera Zeiss MC 80 DX, acoplada ao microscópio Zeiss Axioplan. Este equipamento foi fornecido pelo Departamento de Estratigrafia e Paleontologia da FGEL-UERJ, onde as lâminas estão catalogadas e armazenadas. 
A integração dos resultados a partir das descrições de campo e posteriores análises de laboratório permitiu o agrupamento de associações de fácies, para interpretação de seus respectivos ambientes deposicionais.

\section{RESULTADOS}

As fácies deposicionais que foram identificadas nas seções correspondentes estão baseadas nas descrições de quatro afloramentos situados na região Alto de Olivença, no Estado da Bahia. Na cidade de Ilhéus, no afloramento localizado em frente ao aeroporto (Figura 1 - Ponto 02), predominam fácies de arenitos com estratificações cruzadas de baixo ângulo e acanalada. Na região do litoral sul em direção à cidade de Una, os principais afloramentos localizam-se no lado oeste da rodovia BA001. Tais afloramentos foram caracterizados a partir de três perfis estratigráficos nos Pontos 05, 06 e 07 (Figura 2) e mostramse constituídos por sucessões de arenito médio a grosso argilitos e folhelhos negros, cujos ciclos deposicionais são marcados por arranjos granocrescentes ascendentes nas seções, com camadas de folhelhos pretos na base do ciclo.

\section{Análises faciológicas}

Fácies arenito sigmoidal. Esta fácies é caracterizada por arenito grosso, ocasionalmente apresenta seixos dispersos, mal selecionados, friável, feldspático, de coloração cinza escuro a preto, ou, por vezes, amarelado, com estratificação sigmoidal. Os estratos mostram geometria de lobos, com espessuras médias de 40 a $60 \mathrm{~cm}$, que exibem granodecrescência ascendente. Os lobos sigmoidais são nitidamente observados na porção superior da coluna estratigráfica do Ponto 06 (Figura 2A). Estes corpos constituem-se, ocasionalmente, por arenito muito grosso, ou com grânulos imbricados, mal selecionados, com geometrias de 2 a 4 m de extensão. Nessa posição estratigráfica estes lobos estão em contato abrupto com fácies pelíticas, evidenciando uma passagem brusca de energia, com chegada de material grosso ao sistema. Estas fácies depositaram-se na região de maior energia na região intermaré, próximo ao nível de maré baixa, sendo os mesmos considerados como registros de depósitos de ebb tidal delta.

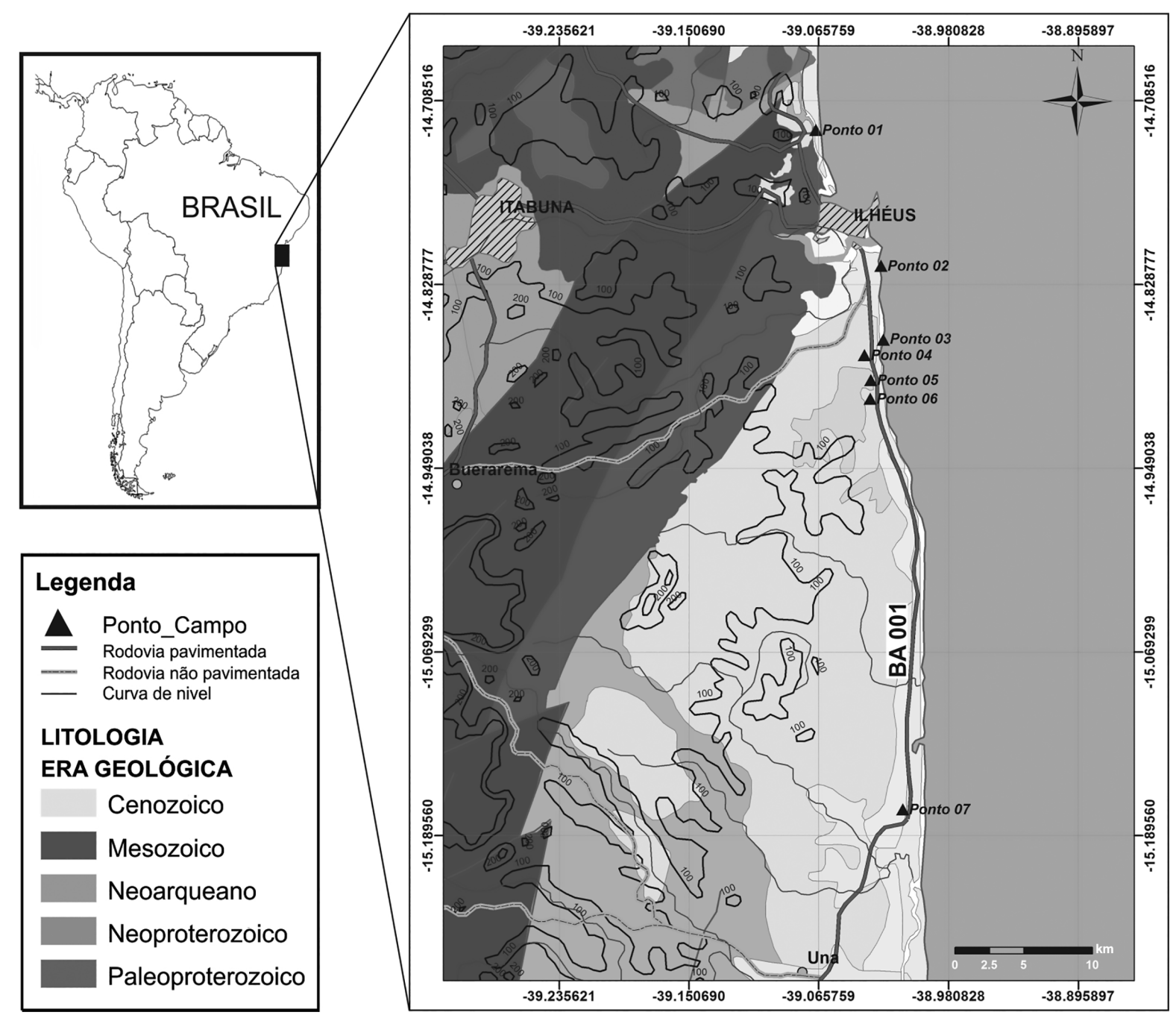

Figura 1. Localização geográfica e geológica da área de estudo. $\Delta$ Mapa de localização dos afloramentos estudados.

Figure 1. Geographic and geological location of the study area. $\mathbf{\Delta}$ Location map of the studied outcrops. 
Fácies arenito com estratificação cruzada. Esta fácies é constituída por estratos de arenito médio a grosso, de seleção moderada, com geometrias tabulares. Os contatos inferiores das camadas são retos. A ocorrência de estratificações cruzadas com paleocorrentes bidirecionais aponta para a influência de processos de maré. Na porção inferior do Ponto 07 (Figura 2B), representado no perfil estratigráfico, são observados arenitos de granulometria média com estratificação cruzada. As medidas de paleocorrentes nestas estratificações cruzadas indicam padrão de correntes bidirecionais (fluxos para NW e ENE). Tais estratos são aqui interpretados como registros de barras de maré, representando geometrias verticalmente contíguas que se desenvolveram abaixo do nível de maré baixa como corpos arenosos paralelos e alongados na direção da corrente de maré. Neste contexto, a corrente ENE (dominante) corresponde à corrente de vazante.

Fácies arenito com laminação plano-paralela. Arenito fino a médio, bem selecionado, esbranquiçado, localmente cinza claro, com grânulos angulares, apresentando ocasionalmente pequenas lentes de lama. Em geral, as camadas possuem geometria tabular. Os estratos com laminação plano-paralela são constituídos por lâminas ou níveis delgados, marcados por gradação normal. As estruturas presentes nesta fácies são formadas em condições de baixa a média energia, produto de fluxos oscilatórios. Na porção inferior da coluna estratigráfica do Ponto 05 (Figura 2C) observa-se a estratificação de baixo ângulo a quase planar, provavelmente gerada pela combinação de fluxo oscilatório e unidirecional. Esta fácies é interpretada como registro da migração de barras em um contexto de planície de maré. No referido ponto observa-se uma fácies arenosa com seixos intercalada aos depósitos de baixo ângulo, com deposição provavelmente associada a movimentos rápidos de massa de sedimentos, devido a uma momentânea instabilidade da bacia estuarina.

Fácies arenito com estratificação cruzada acanalada. Ocorrem arenitos grossos, amarelados, mal selecionados, com estratificação cruzada acanalada, marcados em geral pela presença de níveis de seixos quartzosos na base, dispostos em arranjos granodecrescentes. As características desta fácies sugerem deposição associada aos canais de maré. No Ponto 02, também se observam corpos de arenitos médios com estratificação cruzada acanalada, intercalados com estratos de arenito médio com estratificação cruzada planar. Na base da seção, na fração cascalhosa dos arenitos, predominam grãos com tamanho grânulo e seixo. A variação granulométrica nos arenitos (de médio a grosso) reflete a presença de maior energia por entrada de material fluvial. As estruturas esféricas e concêntricas observadas nas superfícies das camadas são produto do intemperismo recente, pela ação das ondas. Essas
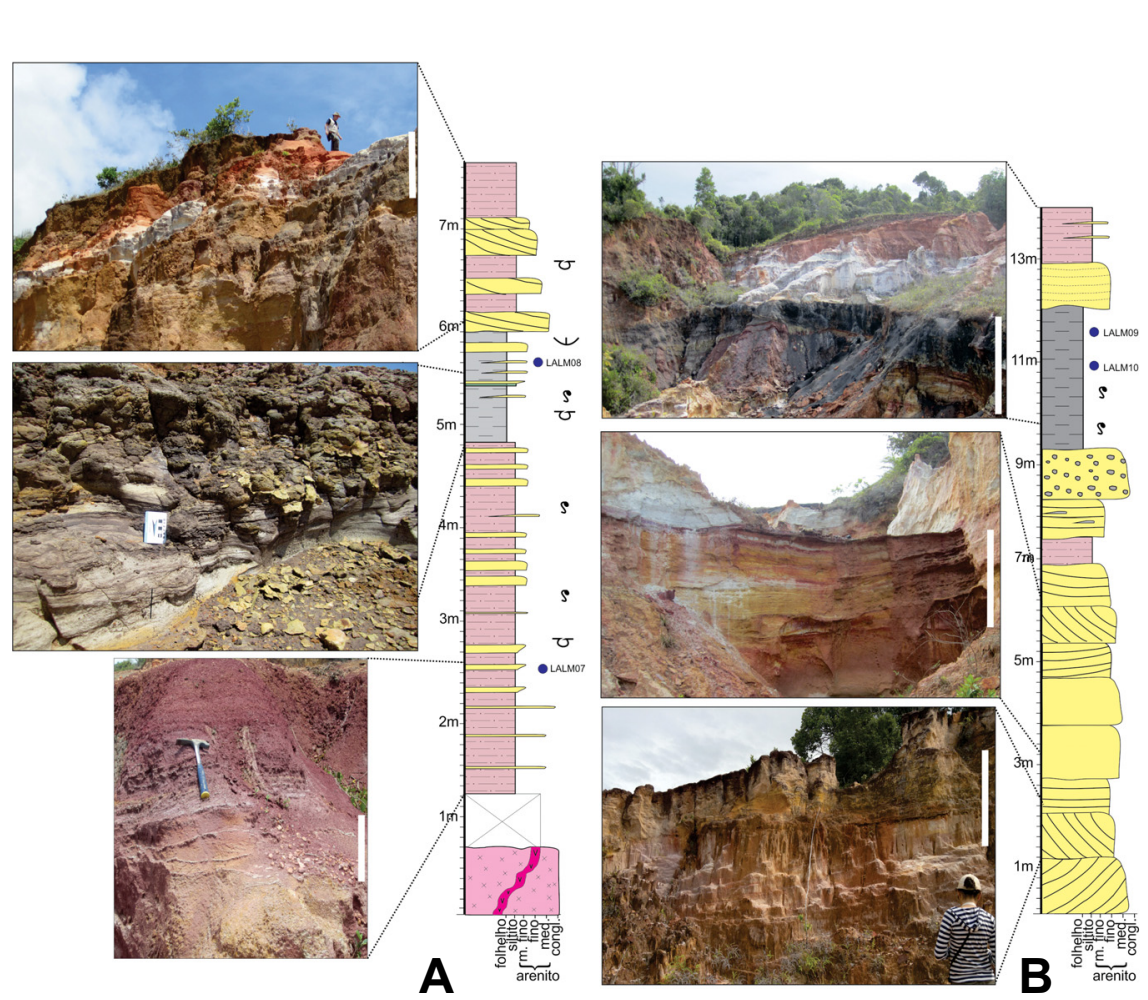

Estruturas

Estratificação cruzada

Plano paralela

Sigmoidal

Estruturas

de deformação

s Bioturbação

Seixos imbricados

¿ Fluidização

v Estructuras de carga

$\triangle$ Granodescresência ascendente

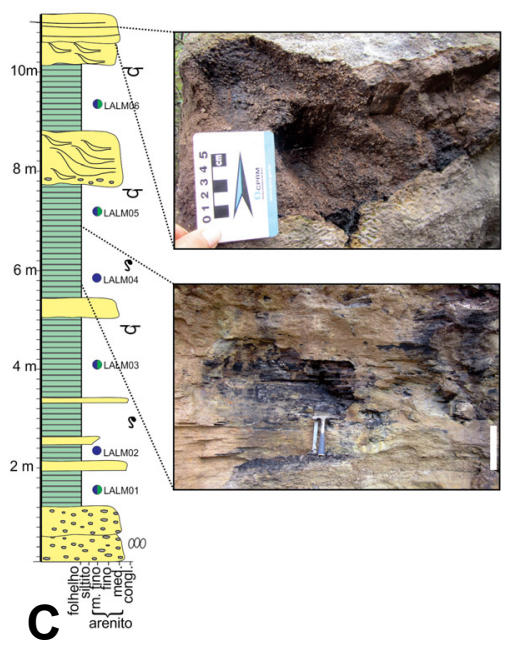

Figura 2. Perfil estratigráfico composto da Formação Barreiras mostrando o empilhamento sedimentar. A, perfil estratigráfico Ponto 06 . B, perfil estratigráfico Ponto 07. C, perfil estratigráfico Ponto 05. As fotos exemplificam as estruturas sedimentares e geometrias observadas no afloramento. Escalas: $A, C=50 \mathrm{~cm} ; B=1 \mathrm{~m}$.

Figure 2. Schematic sections of the Barreiras Formation, showing vertical distribution of facies associations. A, stratigraphic section of Point 06 ; B, stratigraphic section of point Point 07; C, stratigraphic section of Point 05 . The pictures illustrate the geometries and sedimentary structures observed in outcrop. Scale bars: $A, C=50 \mathrm{~cm} ; B=1 \mathrm{~m}$. 
camadas apresentam mergulho suave em direção ao mar, paralelas à linha de costa, o que pode ser considerado como indicador do nível do mar.

Fácies arenito maciço. Arenitos de granulometria fina a grossa, maciços, mal selecionados, podendo conter grânulos de quartzo dispersos. Ocorrem como camadas tabulares ou lenticulares de $0,5 \mathrm{~m}$ de espessura. Na parte basal do perfil estratigráfico do Ponto 07 (Figura 2B) possuem alguns metros de extensão e estão intercaladas com as fácies de arenito com estratificação cruzada acanalada. As camadas maciças por vezes podem apresentar base erosiva. Desta forma, as camadas maciças são interpretadas como fluxos de massa hiperconcentrados gerados durante períodos de fortes enxurradas.

Fácies arenito grosso com grânulos. Arenitos grossos, com grânulos e seixos, mal selecionados, de coloração marrom-esbranquiçada, com estratificação cruzada de baixo ângulo, dispostos em camadas canalizadas são observados nos afloramentos Ponto 06 e 07 e foram interpretados como registro da variação de descarga de um sistema fluvial, depositados em condições de mais alta energia nos topos das barras. A presença de clastos imbricados sugere um transporte por carga trativa em condições de alta energia em canais fluviais, refletindo o aporte de material fluvial mais grosso por variação de descarga de um sistema fluvial em um sistema estuarino com influência de maré.

Fácies argilito avermelhado. Argilito avermelhado a variegado com incipiente laminação em direção ao topo. $\mathrm{Na}$ seção estratigráfica do Ponto 05 (Figura 2C) observam-se as fácies de argilito avermelhado predominantemente na base, com lentes de arenito fino intercaldas. No topo da seção (Ponto 05), intercalam-se ao argilito as fácies de arenito grosso com estratificação cruzada de baixo ângulo a ligeiramente paralela. A fácies argilito avermelhado foi depositada em um ambiente subaquoso de baixa energia que apresentava variações periódicas de condições energéticas típicas de ambiente supramaré.

Fácies folhelho cinza. Folhelho síltico-argiloso intercalado com camadas delgadas ou lâminas de arenito. Os mesmos são cinza, ligeiramente escuros ou esbranquiçados, bioturbados, com incipiente estratificação laminar e wavy, estruturas de fluidização e níveis superficiais de calcrete no topo. Alternam cores marrom-amareladas com pequenas lentes de arenito fino. Feições de escorregamento denotam atuação de processos rápidos de sedimentação como pôde ser observado no Ponto 05. A presença de estruturas de fluidização nas seções é decorrente de uma rápida deposição em um ambiente subaquoso. As alternâncias de lentes de arenito sugerem variações de energia relacionadas às correntes de maré, que em áreas intramaré superior produzem depósitos rítmicos de granulometria variável. As camadas de arenito muito fino com ligeiras marcas onduladas e lâminas de pelito podem ser atribuídas a um domínio misto (fluvial/maré) do estuário na zona de intermaré pouco profunda. A presença de níveis de calcrete sugerem episódios de mínima excursão de maré que marcaria exposições subaéreas.

Fácies folhelho papiráceo. Folhelho papiráceo, bem laminado, preto, com restos de vegetais, com presença de bioturbação, alto teor de enxofre na superfície e teores elevados de COT entre 18 e 22\% aflorante no Ponto 06 (Figura $2 \mathrm{~A})$. O teor de enxofre oscila entre $11 \mathrm{e} 16 \%$. Os folhelhos apresentam manchas amareladas irregulares com forte odor. Esta fácies é resposta da sedimentação de pelitos com matéria orgânica algálica e terrestre em ambiente subaquoso com limitada circulação de oxigênio, de caráter anóxico o que indica condições de planície de maré.

Fácies folhelho carbonoso. Folhelho betuminoso, preto carbonoso, com pouca presença de bioturbação, apresenta coloração amarela na superfície pelo teor de enxofre. Os mesmos estão presentes no topo da seção estratigráfica medida no Ponto 07. Os altos teores de COT, superiores a $20 \%$ pressupõem uma maior contribuição de matéria orgânica de origem terrestre em ambiente sub-aquoso em condições de pântano.

Com base nas informações faciológicas foi possível gerar um modelo de associação de fácies que melhor representasse a unidade estudada. Esta interpretação, por sua vez, serviu de base para o modelo estratigráfico do ambiente deposicional dos sedimentos.

\section{Análises geoquímicas}

As variações sedimentológicas e geoquímicas dos níveis pelíticos descritos nos afloramentos permitem diferenciar claramente três dessas fácies pelíticas, conforme descrito no item anteior. A partir das características sedimentológicas, em combinação com os parâmetros geoquímicos de teores de carbono total, Pirólise Rock-Eval e biomarcadores, foram inferidas as características no ambiente deposicional e no tipo de matéria orgânica presente, conforme abaixo apresentado.

Na Fácies folhelho papiráceo, os teores de COT variam entre 17 e $30 \%$ e os teores de enxofre variam entre 12 até $30 \%$. Já os valores de resíduo insolúvel situam-se em torno de $90 \%$, indicando uma sedimentação essencialmente silicilástica. Usando-se os valores de Índice de Hidrogênio (IH) e de Índice de Oxigênio (IO) obtidos a partir de pirólise RockEval, e aplicando-os em um diagrama do tipo "Van Krevelen" (Figura 03), foi possível diferenciar que a matéria orgânica se comporta como Tipo IV, ou seja, uma matéria orgânica principalmente de origem terrestre oxidada (Peters, 1986).

Os depósitos da fácies folhelho cinza são caracterizados por teores comparativamente mais baixos de carbono orgânico total, porém ainda assim elevados (entre 4 e $6 \%$ ), e teores relativamente mais baixos de enxofre total $(0,7 \%)$. Os valores de COT para as fácies folhelho carbonoso são bastante variáveis, entre $22 \%$ e $38 \%$, e são superiores aos constatados nos folhelhos papiráceos com uma diminuição no conteúdo de enxofre total (5\%). As amostras de folhelhos que apresentam manchas amareladas irregulares com forte odor de enxofre diminuem os teores de carbono que oscilam entre 11 e $16 \%$. No Ponto 07 (Figura 2B), os folhelhos desta fácies possuem teores elevadíssimos de COT em torno de até 35\%. Deve ser destacado que a mesma fácies de folhelho carbonoso no ponto 06 , localizada a $30 \mathrm{~km}$ do ponto 07 , apresenta valores menores de COT, em torno de $18 \%$. Uma explicação para este fato poderia ser que estes folhelhos foram depositados em ambientes ligeiramente distintos. Enquanto os folhelhos 


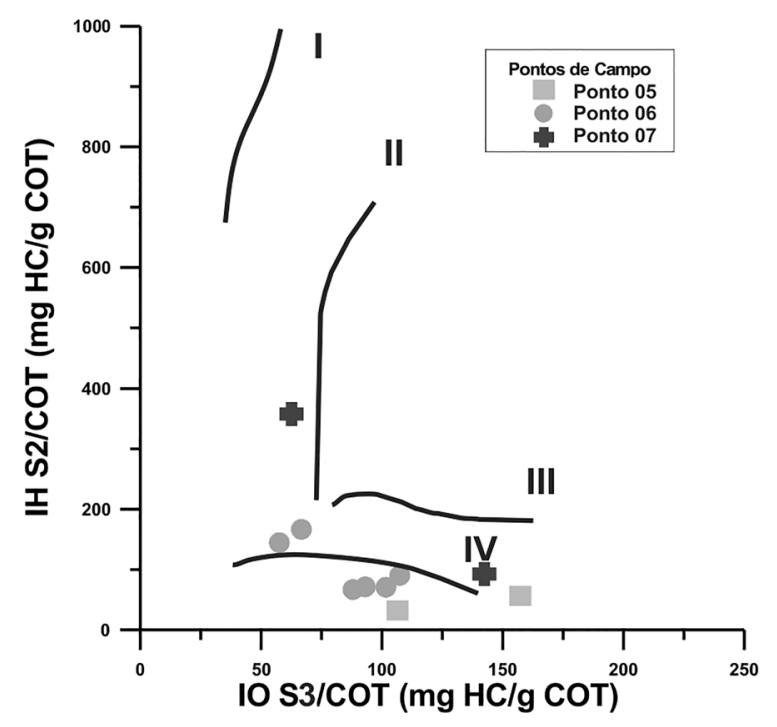

Figura 3. Diagrama tipo "Van Krevelen" modificado, índice de hidrocarbonetos (IH) versus índice de oxigênio (IO). A partir das amostras foi possível diferenciar matéria orgânica preferencialmente como tipo IV, sem potencial para geração de hidrocarbonetos. HC (hidrocarbonetos) e $\mathrm{CO}_{2}$ calculados a partir da pirólise Rock-Eval. COT, carbono orgânico total.

Figure 3. Modified Van Krevelen diagram of the hydrocarbon index (IH) vs. oxygen index (IO). Little to no remaining hydrocarbon generation potential is indicated for the samples. $\mathrm{HC}$ (hidrocarbons) and $\mathrm{CO}_{2}$ from Rock-Eval pyrolysis. COT, total organic carbon.
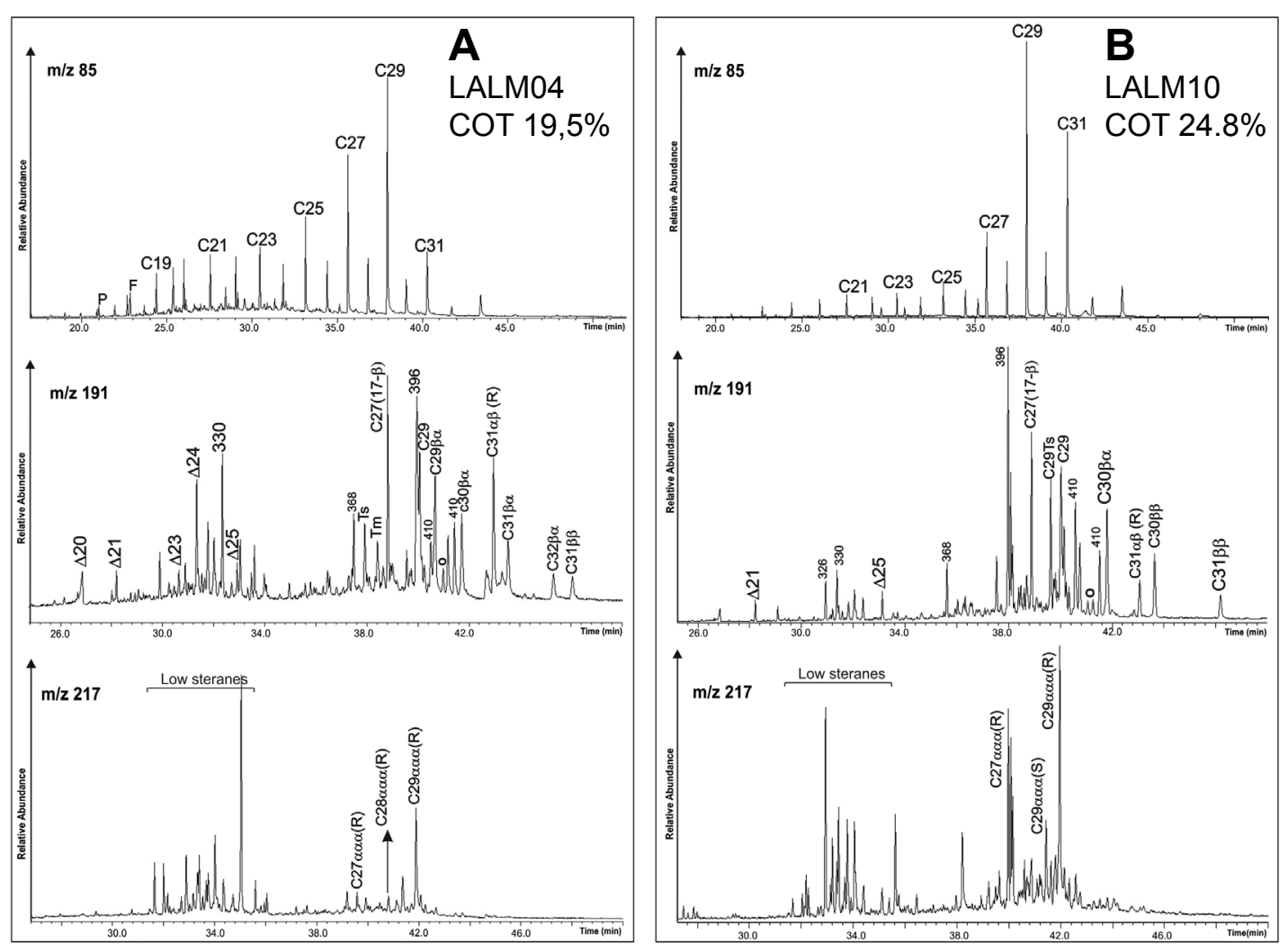

Figura 4. Biomarcadores de GC-MS fração saturada para as fácies de folhelhos, fragmentograma m/z 85 (alcanos lineares), $\mathrm{m} / \mathrm{z} 191$ (terpanos), $\mathrm{m} / \mathrm{z}$ 217 (esteranos). A, fácies folhelhos papiráceo, amostra LALM04, Ponto 6. B, fácies folhelhos carbonoso, amostra LALM10, Ponto 7. Abreviações:

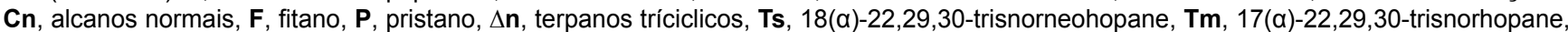
G, gamacerano, $\mathbf{O}$, oleanano, COT, carbono orgânico total.

Figure 4. Biomarker, examples of GC-MS data showing m/z 85 (n-alkanes biomarkers), m/z 191 (terpanes biomarkers) and $\mathrm{m} / \mathrm{z} 217$ (steranes biomarkers) of saturated fractions from shale facies. A, papyraceous shale sample LALM04, Point 6. B, carbonaceous shale, sample LALM10, Point 7. Abbreviations: $\mathbf{C n}$, normal alkane; F, phytane, P, pristane, $\Delta \mathbf{n}$, tricyclic terpane, Ts, 18( $\alpha)$-22,29,30-trisnorneohopane; Tm, 17( $\alpha$ )22,29,30-trisnorhopane; G, gammacerane, O, oleanane. COT, total organic carbon. 
mais carbonosos, com maiores teores de COT, se depositariam em ambiente com maior aporte de matéria orgânica terrestre, raso restrito, onde é menor a circulação de água, aumentando a taxa de anoxia e favorecendo maior preservação, condições sugeridas por pântano salobro. Já os folhelhos com menores teores de COT depositaram-se em ambiente raso aberto ou com maior circulação de água, o que indica condições de planície de maré correspondente ao Ponto 06.

A partir das análises de biormarcadores nas diferentes fácies de folhelhos, observam-se características similares: na fácies de folhelho papiráceo constata-se a presença de alcanos de baixo peso molecular $\left(\mathrm{C}_{17}-\mathrm{C}_{22}\right)$. Contudo, a predominância dos alcanos lineares de alto peso molecular predominam no grupo $\left(\mathrm{C}_{27}, \mathrm{C}_{29}\right.$ e $\mathrm{C}_{31}$ ) observados no fragmentrograma m/z 85 (Figura 4A), com alto grau de imparidade, a alta abundância do hopano $\mathrm{C}_{29} \alpha \beta$ sobre o norhopano $\mathrm{C}_{30} \alpha \beta$; as elevadas proporções entre os moretanos: trisnorhopano $\mathrm{C}_{27}(17 \beta), \mathrm{e}_{30} \beta \alpha$; e a presença do terpano tricíclico $\mathrm{C}_{24}$, identificados no íon $\mathrm{m} / \mathrm{z} 191$, pressupõe uma contribuição predominante de matéria orgânica de origem terrestre para os folhelhos papiráceos (Bray \& Evans, 1961). A presença de $18 \alpha(\mathrm{H})$-Oleanano, composto característico de plantas terrestres da família das angiospermas (Ekweozor \& Udo, 1988), ocorre principalmente em bacias terciárias em ambientes deltaicos (Brooks et al., 1969) ou em óleos do Cenozoico e Neocretáceo (Peters et al., 2005).

O leve aumento das razões dos esteranos $\mathrm{C}_{27}$, estudados no fragmentograma m/z 217 (Figura 4B), observados na fácies dos folhelhos carbonosos pode indicar uma contribuição de algas na matéria orgânica, que comparada com os folhelhos papiráceos, indicariam uma deposição principalmente de matéria orgânica mista (Huang \& Meischein, 1979; Peters et al., 2005). No entanto, a contribuição de plantas terrestres prevalece no grupo, observada pela predominância do esterano $\mathrm{C}_{29} \alpha \alpha \alpha \mathrm{R}$, a relação Hopano/Esterano superior a 4 (quatro) e a presença, embora em baixas proporções, de $18 \alpha$ (H) Oleanano identificado no íon $\mathrm{m} / \mathrm{z} 191$.

O predomínio de compostos insaturados no fragmentograma $(\mathrm{m} / \mathrm{z} 191)$ relativos aos terpanos, correspondentes as massas
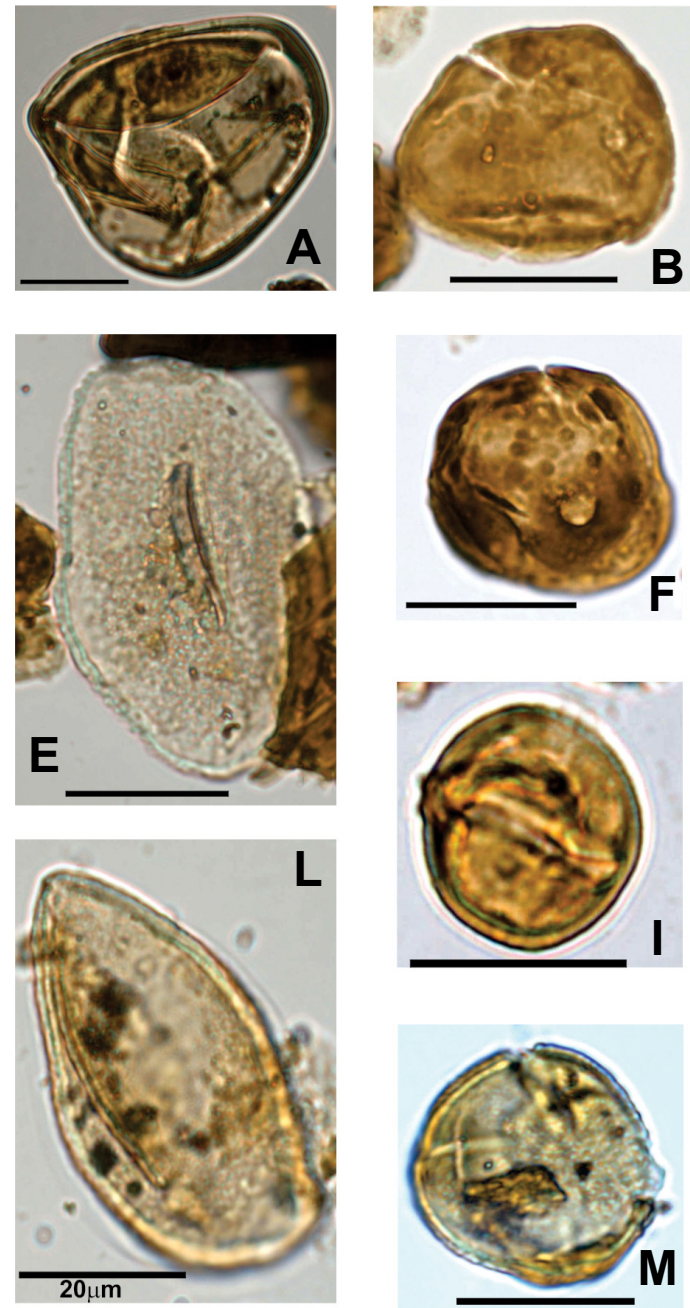
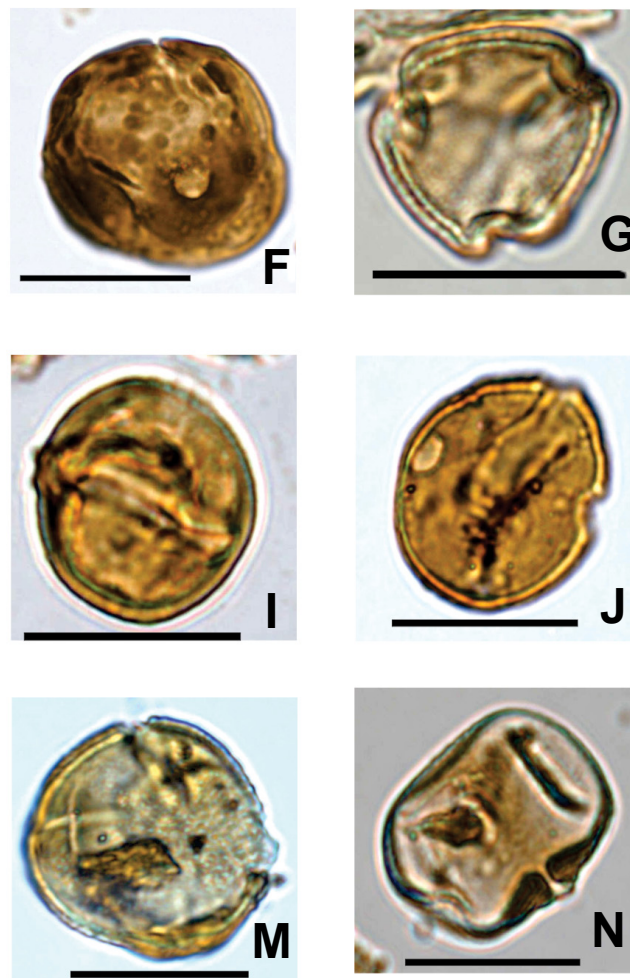
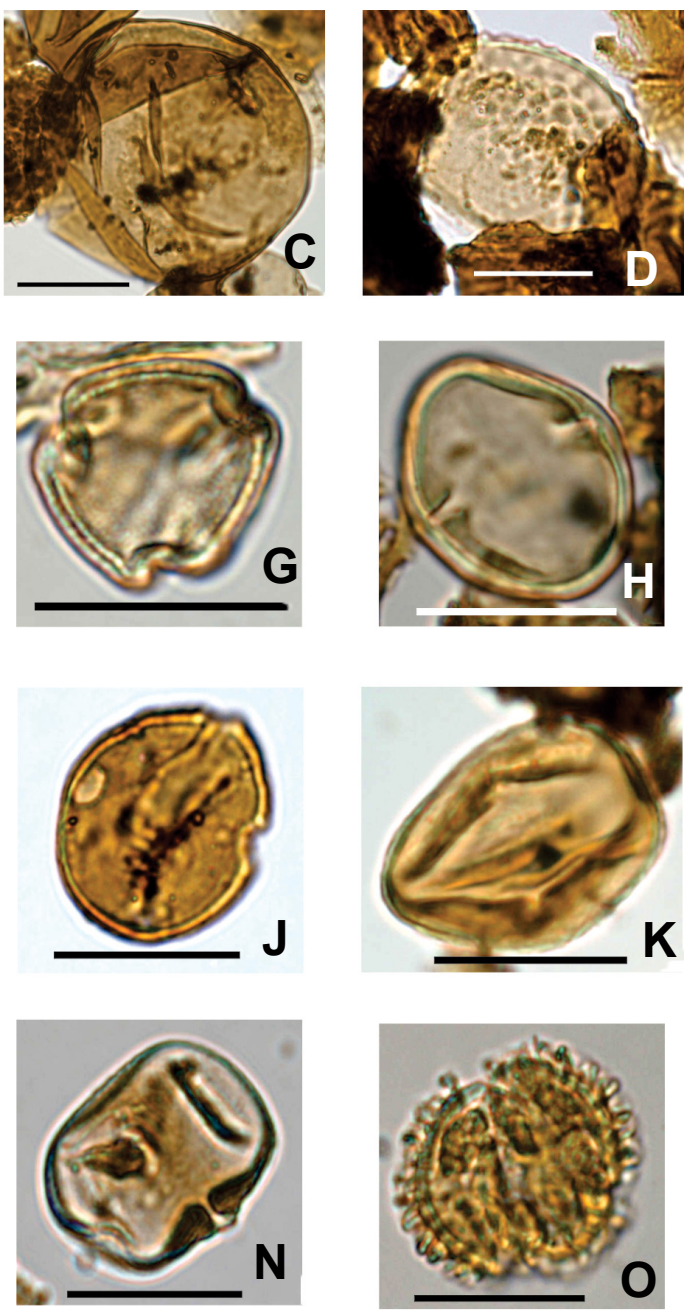

Figura 5. Fotomicrografias de espécies selecionadas. A, Deltoidospora adriennis; B, Laevigatosporites tibuensis; C, ?Araucariacites sp.; D, Verrucatosporites usmensis; E, Retimonocolpites sp.; F, Monoporopollenites annulatus; G, Psilatricolpites sp.1; H, Psilatricolpites sp. 2; I, Psilatricolpites divisus; J, ?Parsonsidites sp. K, Tricolporopollenites edmundii; L, Retimonocolpites cf. R. maximus; M, Zonocostites sp.; $\mathbf{N}$, Tetracolporopollenites transversalis; $\mathbf{O}$, Ilexpollenites sp. Escalas $=20 \mu \mathrm{m}$.

Figure 5. Photomicrographs of selected species. Scale bars $=20 \mu \mathrm{m}$ 
410, 396 e 368 (Figura 4A), bem como as altas proporções de moretanos $\left(C_{27}(17 \beta), C_{29} \beta \alpha, C_{30} \beta \alpha\right)$, constituem evidências da baixa maturação térmica da matéria orgânica. A predominância dos epímeros $\mathrm{R}$ sobre a $\mathrm{S}$ nos hopanos estendidos $C_{31}(\alpha \beta R)$, (Figura $4 B$ ), juntamente com os baixos valores da razão $C_{29} \alpha \alpha \alpha 20 R / C 29 \alpha \alpha \alpha S$ esterano $(0,06-0,09)$ confirmam a baixa evolução térmica da matéria orgânica (Moldowan et al., 1983, 1985).

\section{Análises palinológicas}

Apesar de se constituir dominantemente com camadas conglomeráticas e de areias grossas, além de estratos argilosos de coloração variegada, geralmente oxidada, os sedimentos estudados apresentam, localmente, camadas de folhelhos cinza escuro a pretos, favorecendo a preservação de palinomorfos.
No estudo em questão, objetivando integração com estudos palinoestratigráficos foram coletadas três amostras representativas das fácies de folhelho cinza, folhelho carbonoso e folhelho papiráceo (Figura 7). Todas as amostras analisadas apresentaram-se férteis, com concentrações satisfatórias de palinomorfos em bom estado de preservação. A palinoflora recuperada é constituída essencialmente por palinomorfos continentais, tais como algas, fungos, briófitas, pteridófitas, gimnospermas e angiospermas (Figura 5). Entretanto, apesar de escassos, fazem-se também presentes palinomorfos de origem marinha, principalmente do grupo dos palinoforaminíferos (Figura 6H). Os grãos de pólen afins às angiospermas, particularmente os tricolpados e, em menor quantidade, os monocolpados, dominam a associação.

O resíduo orgânico é dominado por elementos de origem continental, principalmente de matéria orgânica lenhosa,
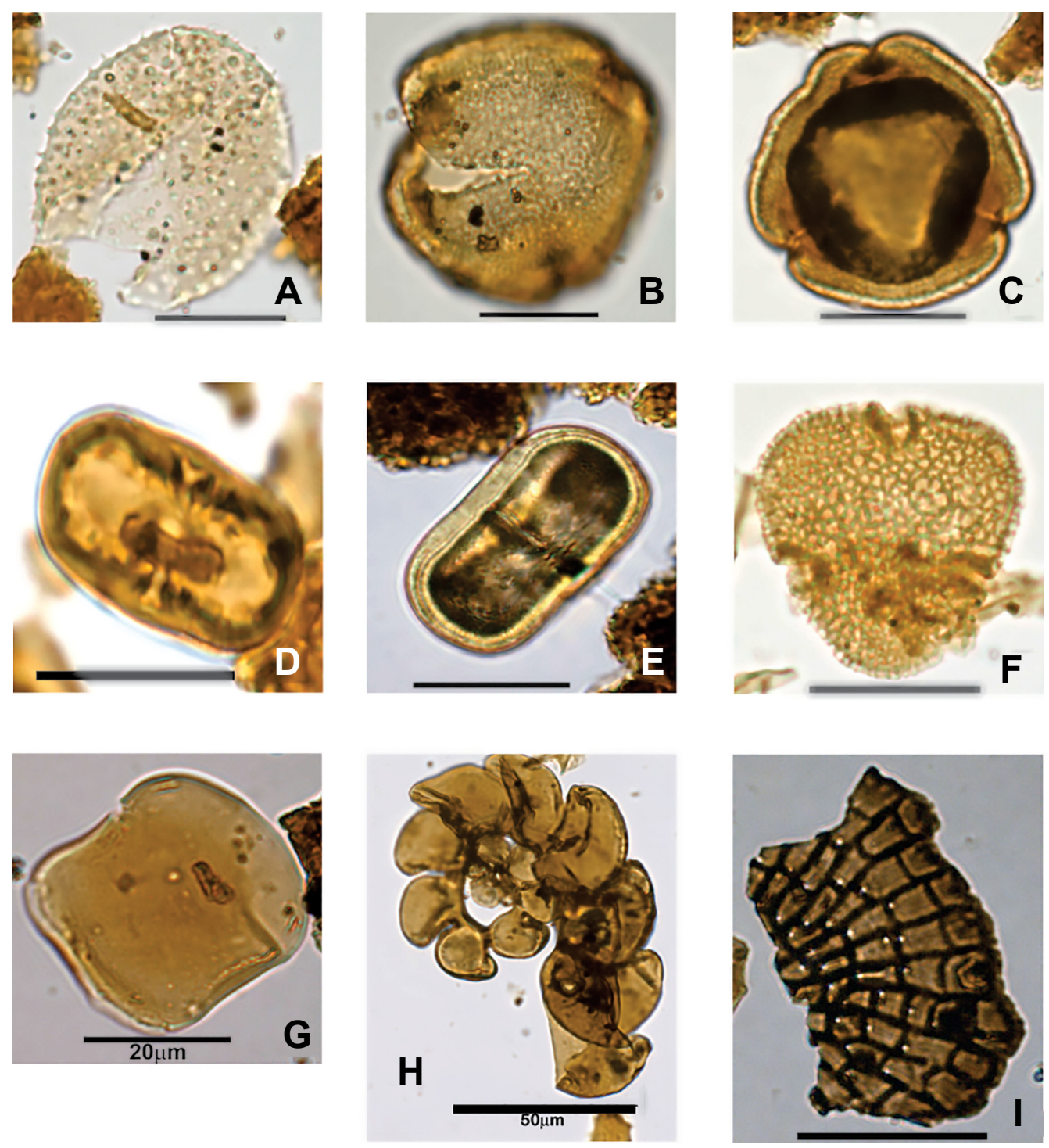

Figure 6. Fotomicrografias de espécies selecionadas. A, Mauritiidites franciscoi; B, Lanagiopollis crassa; C, Brevitricolporado sp.; D, E, Multiareolites formosus; F, Bombacacidites clarus; G, Algae cf. Balmeela sp.; H, Palinoforaminífero; I, Callimothallus sp. Escalas: A-G = 20 $\mu \mathrm{m} ; \mathrm{H}=50 \mu \mathrm{m} ; \mathrm{I}=20 \mu \mathrm{m}$.

Figure 6. Photomicrographs of selected species. Scale bars: $A-G=20 \mu \mathrm{m} ; \mathrm{H}=50 \mu \mathrm{m} ; \mathrm{I}=20 \mu \mathrm{m}$. 
que indica forte contribuição alóctone e maior proximidade à linha de costa, em condições de relativa energia de deposição para esse material. Praticamente não contém matéria orgânica amorfa.

Em termos bioestratigráficos, as formas identificadas, mais significativas, contam com a presença das espécies: Deltoidospora adriennis (Figura 5A), Retimonocolpites cf. R. maximus (Figura 5E), Psilatricolpites divisus (Figura 5I), Lanagiopollis crassa (Figura 6B) e Multiareolites formosus (Figura 6D). Dentre os elementos mais importantes da palinoflora identificada estão os gêneros Bombacacidites (B. clarus), Mauritiidites (M. franciscoi) e Ilexpollenites (Ilexpollenites sp.). A não identificação de formas-guias impossibilitou a definição de palinozonas para a seção. Contudo, as ausências de Crassoretitriletes vanraadshoovenii e de Grimsdalea magnaclavata bem como a presença constante de Ilexpollenites sp., sugerem, de acordo com os dados apresentados por Leite et al. (1977) e Leite (2004), que os estratos ora analisados foram depositados no Mioceno.

\section{DISCUSSÃO E INTERPRETAÇÕES}

\section{Modelo estratigráfico e reconstrução paleoambiental}

A integração baseada nos dados obtidos em campo, nos resultados das análises geoquímicas e palinológicos permitiu melhor compreensão dos diferentes paleoambientes, que regiram esta sedimentação. Para construir um modelo de distribuição horizontal dos elementos descritos e reconstruir as características deposicionais do sistema que gerou os sedimentos estudados, foram buscados critérios que pudessem distinguir a proximidade e distalidade em relação à linha de costa (Dalrymple et al., 1992). Os sistemas costeiros representam áreas em que atuam vários mecanismos de distribuição e deposição de sedimentos, tanto ligados à atividade de ondas, como às atividades de maré, que determinam as propriedades das fácies e a geometria dos corpos sedimentares (Dalrymple \& Choi, 2007).

Nas seções, as estruturas sedimentares atribuídas à influência de maré permitiram a reconstituição do sistema deposicional para estes depósitos. O modelo produzido pressupõe que na sucessão estudada (300 $\mathrm{m}$ de seção linear) não existem variações substanciais do sistema deposicional. Os três afloramentos descritos distribuem-se de modo bastante uniforme na área estudada, sugerindo certa continuidade do sistema deposicional, por uma extensão de $50 \mathrm{~km}$.

Os componentes dinâmicos para sedimentação de estuários são controlados pela relação entre a variação do nível do mar e a entrada de sedimentos, pois esses depósitos são resultantes de uma transgressão, que é uma condição necessária para a formação de estuários. Entende-se que os estuários normalmente são implantados no inicio da transgressão e continuam depositando sedimento até a superfície máxima de inundação (Boyd et al., 2006). O melhor desenvolvimento dos estuários ao longo do tempo dar-se-á, preferencialmente, nos tratos transgressivos e de mar alto, pois, ao serem analisados dentro da dinâmica de sedimentação costeira, terão papel fundamental na caracterização das rochas decorrentes das variações cíclicas do nível do mar. As recorrências verticais das barras estuarinas com sedimentos finos marinhos marginais ajudaram a estabelecer as superfícies chave nos afloramentos 05 e 06 (Figuras $2 \mathrm{C}$ e 2A).

Pelas feições sedimentares observadas a partir das seções estratigráficas, e por sua associação com as demais fácies, interpretou-se, para esta associação, um predomínio da condição de inframaré/intermaré. Um ponto relevante sobre estes intervalos argilosos é definir o grau da influência marinha e, com isto, estabelecer a relação de pulsos transgressivoregressivos. Para isto, utilizaram-se as informações palinológicas provenientes dos níveis dos folhelhos, assim como, os altos teores de COT, para serem posteriormente integradas a uma análise conjunta da estratigrafia de sequências.

A superfície transgressiva foi definida na base dos folhelhos papiráceos, marinhos marginais (Figura 2A Ponto 06) localizado no areal Jarumeira, posicionado em frente à Praia de Cururupe, em concordância com os dados palinológicos, onde na base do afloramento se observa arenito grosso com grânulos, seguido de folhelho papiráceo com alto teor de enxofre na sua superfície, intercalados com arenito grosso com estratificação sigmoidal e com estrutura de carga, indicando uma variação de energia num ambiente distal, e entrada de material mais grosso para o sistema. Esta condição coincide com as interpretações palinológicas que são marcadas pela presença de palinoforaminíferos, aliado as raras algas e à presença significativa de palinomorfos continentais junto com material orgânico lenhoso indicando uma sedimentação em um ambiente marinho raso, costeiro ou mesmo lagunar, com uma forte influência de aporte continental. Os altos teores de carbono orgânico e enxofre total para esta unidade caracterizam o trato de sistema transgressivo (Leventhal, 1983), o que contribui para condições adequadas de preservação da matéria orgânica. Os mesmos associamse aos pulsos de afogamento provocados pelos períodos de subida do nível do mar. Que evoluem para condições marinhas marginais tendo continuidade lateral nos folhelhos cinza (Figura 2C - Ponto 05), em direção ao norte do Ponto 06 . As fácies de folhelhos cinza são marcadas por valores de COT em torno de $4 \%$, que caracteriza uma matéria orgânica composta predominantemente por vegetais terrestres do tipo IV (oxidada). Esses folhelhos são sobrepostos por camadas de material síltico depositadas em subambiente de planície de maré com feições de exposições subaéreas (calcretes). As fácies de arenitos médios a grossos são associadas a um ambiente deposicional de barras de maré que são marcados por estratos granocrescentes para o topo devido à progradação de fácies arenosas pela ação de maré.

A presença de níveis de folhelho carbonoso (COT de até $40 \%$ ) na parte superior do afloramento (Figura 2B - Ponto 07) caracteriza condições de alto influxo de matéria orgânica num ambiente subaquoso de baixa energia, sugerindo condições paleoambientais de laguna interna salobra, com predominância de influxo de matéria orgânica terrestre. Observam-se ciclos granodecrescentes ascendentes, em geral iniciados na base por arenito médio 


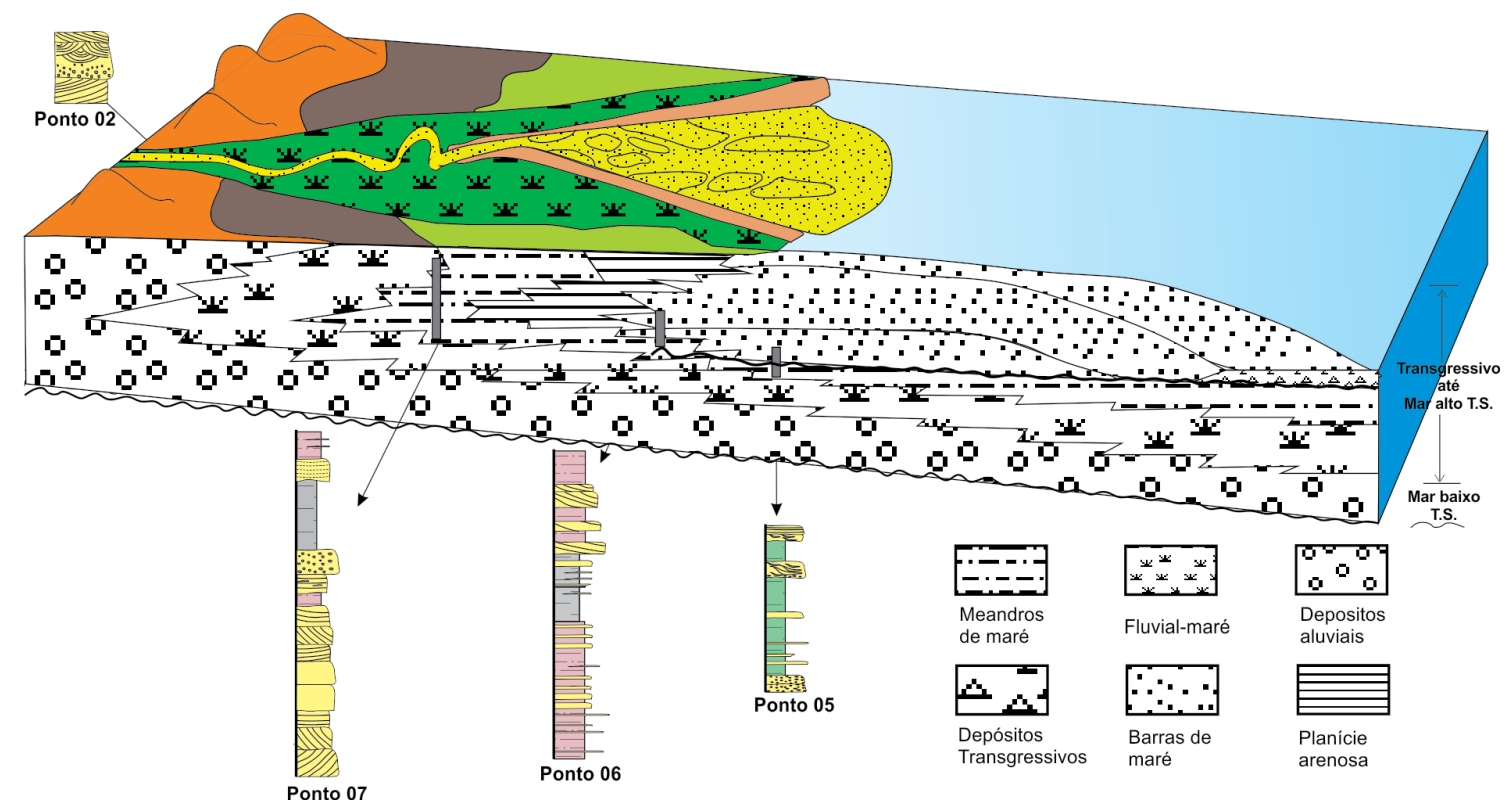

Figura 7. Corte esquemático ao longo do eixo de um estuário dominado por maré, a partir dos perfis de campo. T.S., Trato de Sistema. Modificado de Dalrymple et al. (1992).

Figure 7. Schematic cross-section along the axis of a tide dominated estuary, from the field profiles. T.S., System Tract. Modified from Dalrymple et al. (1992).

com estratificação cruzada e sucedidos verticalmente por arenito com estratificação cruzada de baixo ângulo e arenito maciço. Intercalam-se também neste pacote corpos de arenito com grânulos sem estratificação visível e níveis de argilito, estes compondo estratos isolados ou constituindo lentes delgadas em arenito médio. Esta sucessão de fácies representa condições de maior energia como resposta de ação de maré formando barras com geometrias sigmoidais. Em direção norte, na cidade de Ilhéus, pode-se sugerir que a deposição dos sedimentos expostos sobre a Praia Pontal ocorreu em condições mais proximais associadas à dinâmica dos canais alimentadores do sistema estuarino. Nesta localidade, observam-se estratos pouco espessos de até $30 \mathrm{~cm}$, tabulares, apresentando estratificações cruzadas de baixo ângulo e cruzadas acanaladas. Em relação aos aspectos composicionais, estas fácies são constituídas por grãos predominantemente siliciclástico, representados por quartzo e fragmentos de rocha mal selecionados.

Tanto as informações de biomarcadores e os dados palinológicos como a análise faciológica dos afloramentos permitem sugerir condições paleoambientais que indicam sistema marinho raso lateralmente associado a um complexo litorâneo onde prevaleciam condições de maré ativa, exibindo um característico empilhamento de sistemas marginais progradantes. Baseando-se nestes critérios sedimentológicos foi construído um modelo hipotético de sedimentação costeira, para a área estudada a partir da correlação dos afloramentos, que é caracterizado pela influência de maré (Figura 7).

Na literatura diversos autores descrevem uma transgressão marinha do eomioceno-mesomioceno (no intervalo Aquitaniano - Serravaliano), que seria a responsável pela acumulação de uma grande quantidade de sedimentos nas áreas hoje emersas. Segundo Arai (2006), essa transgressão foi datada especificamente num afloramento em Comandatuba (BA). O referido autor descreve associações palinológicas cuja amplitude estratigráfica estende-se do Oligoceno ao Mioceno médio, sugerindo um caráter marinho para esses sedimentos, na unidade "Barreiras inferior". No entanto, Rosetti (2011), para este intervalo de tempo, caracterizou o evento transgressivo em nível global, que durou até quando o nível do mar sofreu uma queda durante o Tortoniano, a qual deixou um amplo registro sedimentar ao longo de grande parte da costa brasileira. A Formação Pirabas, na região norte do Brasil, a referida autora observou predomínio de depósitos miocênicos transgressivos, correlatos à Formação Barreiras, expostos na costa nordeste brasileira, sugestivo de paleoambientes costeiros.

$\mathrm{Na}$ área mapeada, encontram-se principalmente depósitos de arenito médio a grosso, com seixos, além de arenitos e arenitos argilosos pouco consolidados. Morfologicamente, esta unidade apresenta um relevo ondulado, com colinas de topo convexo a tabular, com altitudes que variam de cerca de $50 \mathrm{~m}$, nas porções mais litorâneas, cerca de $100 \mathrm{~m}$ na borda sul do Alto de Olivença. De acordo com Domingues \& Araujo (2008), estas altitudes médias são compatíveis com as estimativas do nível do mar eustático no Mioceno médioinferior, que alcançou o máximo entre 25 e $100 \mathrm{~m}$ acima do nível atual caracterizando uma transgressão global. Sendo que, subsequente à mesma, o nível do mar sofreu uma forte queda no Tortoniano (Arai, 2006; Rossetti, 2011). No entanto, Arai (2006) sugeriu que após este evento transgressivo, transcorreu uma continuada descida do nível eustático desde o Mioceno médio até o Quaternário, que caracteriza os depósitos fluviais, chamado "Barreiras superior". 
A partir do controle do campo, nos diversos afloramentos observados, e o levantamento dos perfis estratigráficos, focando as principais fácies e estruturas características, sugere-se que os sedimentos descritos neste trabalho e, expostos ao longo da costa sul da Bahia, na região estudada, deveriam ser atribuídos à Formação Rio Doce, já que representariam a porção mais superior da Formação Rio Doce, depositada durante o Mioceno. No entanto, esta unidade tem sido erroneamente mapeada como Formação Barreiras.

Os depósitos estudados neste trabalho foram anteriormente considerados de origem continental, sendo reinterpretados como depósitos estuarinos dominados pela ação de maré. A caracterização destes sedimentos como a Formação Rio Doce é sugerida por evidências constatadas em campo e o uso de ferramentas complementares no contexto deposicional na atual região offshore da bacia.

De acordo com a literatura, a Formação Rio Doce, na bacia de Almada, é principalmente composta por arenitos finos a médios, alternando seixos grossos, de origem continental, acumulados em um complexo litorâneo (Netto \& Sanches, 1991; Netto et al., 1994). Interpretações paleoambientais indicam que os sedimentos relativos a esta formação foram depositados por sistemas fluvio-deltaico e marinho raso, num contexto de fácies marginais progradantes (Gontijo et al., 2007), coerente com a descrição de fácies estudadas e interpretadas para a região onshore da bacia de Almada, observadas em sedimentos anteriormente associados à Formação Barreiras.

Os dados palinológicos corroboram as interpretações exaradas com base nas informações de campo e geoquímicas. A presença de formas continentais aliada a formas marinhas confirmam a interpretação de deposição em ambiente costeiro. A influência marinha é constatada pela presença pequena, mas constante, dos elementos marinhos (palinoforaminíferos), em todos os níveis amostrados. Vale ressaltar que a associação como um todo, apesar de aqui não ter sido realizada uma avaliação quantitativa, é compatível com os dados obtidos por Leite (1997), Leite et al. (1997) e Leite (2004). Estes autores, baseados em análises palinológicas qualitativas e quantitativas, na região Bragantina (Pará) interpretaram que a Formação Barreiras se depositou em ambiente de planície costeira.

\section{CONSIDERAÇÕES FINAIS}

Como anteriormente mencionado, na literatura brasileira não existem estudos estratigráficos e palinológicos integrando a seção miocena preservada junto ao litoral com a seção cronocorrelata das bacias marginais adjacentes. Os dados analisados neste trabalho reforçam idade miocena para os sedimentos aflorantes. A deposição ocorreu dentro de uma progressiva tendência de raseamento, no contexto de um trato de sistemas de mar alto, onde teriam sido desenvolvidos espessos pacotes de argilitos a sílticos de água rasa, intercalados com barras arenosas em um contexto estuarino.

A partir do controle do campo, nos diversos afloramentos observados e, o levantamento dos perfis estratigráficos, focando as principais fácies e estruturas características, sugere-se que os sedimentos aflorantes, mapeados como Formação Barreiras correspondem à Formação Rio Doce mapeada em subsuperfície na área offshore a área estudada.

Os sedimentos aflorantes anteriormente considerados como fluviais, foram reinterpretados neste trabalho como depósitos associados a uma dinâmica estuarina dominada pela ação das marés. Contudo, a tectônica recente local e regional, observada nas bacias de Almada e Jequitinhonha em condições de offshore, pode ter desempenhado um papel importante na preservação final dos depósitos. Pelo fato dos afloramentos se encontrarem em cotas entre 20 e 50 m, não se pode descartar, a possibilidade de que o posicionamento atual reflita a ação de falhas normais recentemente ativas, gerando como consequência as falésias que marcam o litoral sul da Bahia.

Assim, o intervalo estudado, a partir das feições sedimentares, compreenderia a porção mais superior da Formação Rio Doce, depositada no Mioceno. As rochas do intervalo estudado apontam para o predomínio de depósitos de inframaré/intermaré. A análise faciológica, junto com os dados palinológicos e as análises geoquímicas, permitiram a definição de um ambiente estuarino dominado por maré para a deposição desses sedimentos.

A superfície transgressiva foi definida na base dos folhelhos papiráceos pretos, marinhos marginais. Os altos teores de carbono orgânico e enxofre total para esta unidade caracterizam o trato de sistema transgressivo, o que contribui para condições adequadas de preservação da matéria orgânica. Os folhelhos associam-se aos pulsos de afogamento provocados pelos períodos de subida do nível do mar. Os depósitos finos evoluem para condições marinhas marginais tendo continuidade lateral nos folhelhos cinza, em direção ao norte da bacia. Os mesmos são marcados por valores de COT da ordem de $4 \%$ e por uma matéria orgânica composta predominantemente por vegetais terrestres do tipo IV (oxidada). Esses folhelhos são sobrepostos por estratos de material síltico depositados em um subambiente de planície de maré com feições de exposições subaéreas (calcrete). Os folhelhos carbonosos com teores elevados de carbono orgânico (COT de até 40\%) depositaram-se em condições paleoambientais de laguna interna salobra, com predominância de influxo de matéria orgânica terrestre.

Os dados palinológicos, com a presença de formas dominantemente continentais associadas a formas marinhas, corroboram as interpretações de domínio de um ambiente costeiro à época da sedimentação.

Vale ressaltar que os estudos sistemáticos realizados nos depósitos aqui documentados modificam a concepção tradicional da Formação Barreiras no Estado da Bahia, que são tipicamente não estruturados, e de origem fluvial, como comumente descrito na literatura. O trabalho de campo sistemático permitiu detectar afloramentos com excelentes exposições, onde os estudos faciológicos possibilitaram uma reconstituição bastante refinada de processos sedimentares e ambientes de deposição. É possível que um 
estudo mais detalhado no litoral bahiano, possa fornecer novas informações para interpretar adequadamente os ambientes de deposição durante o Mioceno, ao longo do litoral Brasileiro.

\section{AGRADECIMENTOS}

Este estudo foi financiado pela ANP-PRH-17, CNPq, INOG, FAPERJ, aos quais os autores agradecem. Agradecimentos também são devidos ao Departamento de Estratigrafia e Paleontologia (DEPA), e ao LGQM da UERJ pelas análises realizadas.

\section{REFERÊNCIAS}

Arai, M.A. 2006. A grande elevação eustática do Mioceno e sua influência na origem do Grupo Barreiras. Geologia USP, Série Cientifica, 6:1-6. doi:10.5327/S1519-874X2006000300002

Arai, M.A. \& Novais, L.C.C. 2006. Microflora de Comandatuba BA: novos reforços para a idade miocênica do Grupo Barreiras. Porto Alegre, Sociedade Brasileira de Paleontologia, p. 9 (Paleontologia em Destaque 53).

Bezerra, F.H.R.; Mello, C. \& Suguio, K.A. 2006. Formação Barreiras: recentes avanços e antigas questões. Geologia USP, Série Cientifica, 6:3-6. doi:10.5327/S1519-874X2006000300001

Boyd, R.; Dalrymple, R.W. \& Zaitlin, B.A. 2006. Estuarine and incised-valley facies models. In: H.W. Posamentier \& R.G. Walker (eds.) Facies models revisited, Tulsa, Society for Sedimentary Geology, p. 171-236 (Special Publication 84). doi:10.2110/pec.06.84.0171

Bray, E.E. \& Evans, E.D. 1961. Distribution of n-paraffin as a clue to recognition of source beds. Geochimica et Cosmochimica Acta, 22:2-15. doi:10.1016/0016-7037(61)90069-2

Brooks, J.D.; Gould, K. \& Smith, J. 1969. Isoprenoid hydrocarbons in coal and petroleum. Nature, 222:257-259. doi:10.1038/222257a0

Dalrymple, R.W. \& Choi, K. 2007. Morphologic and facies trends through the fluvial- marine transition in tide dominated depositional systems: a schematic framework for environmental and sequence-stratigraphic interpretation. Earth-Science Reviews, 81:135-174. doi:10.1016/j.earscirev.2006.10.002

Dalrymple, R.W.; Zaitlin, B.A. \& Boyd, R. 1992. Estuarine facies models; conceptual basis and stratigraphic implications. Journal of Sedimentary Research, 62:1130-1146. doi:10.1306/ D4267A69-2B26-11D7-8648000102C1865D

Domingues, J.M.L. \& Araújo, L.M.O. 2008. Formação Barreiras: o registro de um onlap costeiro durante o Mioceno. In: CONGRESSO BRASILEIRO DE GEOLOGIA, 44, 2008. Anais, Curitiba, SBG, p. 613.

Ekweozor, C.M. \& Udo, O.T. 1988. The oleananes: origin, maturation, and limits of occurrence in southern Nigeria sedimentary basins. Organic Geochemistry, 13:131-140. doi:10.1016/0146-6380(88)90033-2

Espitalié, J.; Laporte, J.L.; Madec, M.; Marquis, F.; Leplat, P.; Paulet, J. \& Boutefeu, A. 1977. Méthode rapide de caractérisation des roches mètres, de leur potentiel pétrolier et de leur degré d'évolution. Oil \& Gas Science and Technology - Rev. IFP, 32:23-42. doi:10.2516/ogst:1977002

Gontijo, G.M.; Milhomem, P.; Caixeta, J.M.; Dupuy, I.S.S. \& Menezes, P.E.M. 2007. Bacia de Almada. Boletim de Geociencias da Petrobras, 15:463-473.
Huang, W.Y. \& Meischein, W.G. 1979. Sterols as ecologicalindicators. Geochimica et Cosmochimica Acta, 43:739-745. doi:10.1016/0016-7037(79)90257-6

Leite, F.P.R. 1997. Palinofloras neógenas da Formação Pirabas e Grupo Barreiras, área litorânea nordeste do Estado do Pará, Brasil. Instituto de Geociências, Universidade de São Paulo, Dissertação de Mestrado, 102 p.

Leite, F.P.R. 2004. Palinologia. In: D.F Rossetti \& A.M Góes (eds) Neógeno da Amazônia Oriental, Museu Paraense Emílio Goeldi, p. 55-90.

Leite, F.P.R.; Bernardes-de-Oliveira, M.E.C.; Truckenbrodt, W. \& Arai, M. 1997. Palinoestratigrafia da Formação Pirabas e Grupo Barreiras, Mioceno do Nordeste do Estado do Pará, Brasil. Revista Geociências - UnG, 2:141-147.

Leventhal, J.S. 1983. An interpretation of carbon and sulfur relationship in Black Sea sediments as indicators of environments of deposition. Geochimica et Cosmochimica Acta, 47:133-137. doi:10.1016/0016-7037(83)90097-2

Lima, C.C.; Boas, G. \& Bezerra, F.H. 2006. Faciologia e análise tectônica preliminar da Formação Barreiras no litoral sul do estado da Bahia, Brasil. Geologia USP, Série Cientifica, 6:71-80. doi:10.5327/S1519-874X2006000300009

Moldowan, J.M.; Seifert, W.K. \& Gallegos, E.J. 1983. Identification of an extended series of tricyclic terpanes in petroleum. Geochimica et Cosmochimica Acta, 47:1531-1534. doi:10.1016/00167037(83)90313-7

Moldowan, J.M.; Seifert, W.K. \& Gallegos, E.J. 1985. Relationship between petroleum composition and depositional environment of petroleum source-rocks. AAPG Bulletin, 69:1255-1268.

Netto, A.S.T. \& Sanches, C.P. 1991. Roteiro geológico da Bacia do Rio Almada, Bahia. Revista Brasileira de Geociências, 21:186-198.

Netto, A.S.T.; Wanderley Filho, J.R. \& Feijó, F.J. 1994. Bacias de Jacuípe, Camamu e Almada. Boletim de Geociências da Petrobras, 8:173-175.

Obermajer, M.; Fowler, M.G. \& Snowdon, L.R. 1998. A geochemical characterization and a biomarker re-appraisal of the oil families from southwestern Ontario, Canada. Bulletin of Canadian Petroleum Geology, 46:350-378.

Peters, K.E. 1986. Guidelines for evaluating petroleum source rocks using programmed pyrolysis. AAPG Bulletin, 70:318-329.

Peters, K.E.; Walters, C.C. \& Moldowan, J.M. 2005. The biomarker guide: biomarkers and isotopes in the petroleum exploration and Earth history. $2^{\text {nd }}$ ed. Cambridge, Cambridge University Press, $1132 \mathrm{p}$.

Rosetti, D.F. 2011. O registro da transgressão mioceno no Brasil. In: CONGRESSO DA ASSOCIAÇÃO BRASILEIRA DE ESTUDOS DO QUATERNÁRIO, 13, 2011. Resumos expandidos, Armação de Búzios, ABEQUA, p. 1463.

Rossetti, D.F. \& Dominguez, J.M.L. 2011. Evidência na Formação Barreiras do litoral do estado da Bahia. In: CONGRESSO DA ASSOCIAÇÃO BRASILEIRA DE ESTUDOS DO QUATERNÁRIO, 13, 2011. Resumos expandidos, Armação dos Búzios, ABEQUA, p. 1447.

Shimabukuro, S. \& Arai, M. 1999. A transgressão marinha miocênica no Brasil: considerações baseadas no estudo do Grupo Barreiras e da Formação Pirabas. Anais da Academia Brasileira de Ciências, 71:144.

Shimabukuro, S. \& Arai, M. 2000. The Tortonian unconformity: its relation to the stratigraphic framework of the Barreiras Group (Brazilian coastal Cenozoic deposits). In: INTERNATIONAL GEOLOGICAL CONGRESS, 31, 2000. Abstracts, Rio de Janeiro, CPRM, CD-ROM. 
Shimabukuro, S. \& Arai, M. 2001. A Discordância Tortoniana e sua relação com o arcabouço estratigráfico do Grupo Barreiras e unidades correlatas (Neogeno do Brasil). In: CONGRESSO BRASILEIRO DE PALEONTOLOGIA, 17, 2001. Boletim de Resumos, Rio Branco, SBP, p. 54.

Uesugui, N. 1979. Palinologia: técnicas de tratamento de amostras. Boletim Técnico da Petrobras, 22:229-240
Vilas Bôas, G.V.; Sampaio, F.J. \& Pereira, A.M.S. 2001. The Barreiras Group in the Northeastern coast of the State of Bahia, Brazil: depositional mechanisms and processes. Anais da Academia Brasileira de Ciências, 73:417-427. doi:10.1590/ S0001-37652001000300010

Received in November, 2014; accepted in November, 2015. 
Apêndice 1. Táxons de grãos de pólen, esporas, algas de agua doce y palinomorfos marinhos reconhecidos nas fácies estudadas.

Appendix 1. Taxonomic list of the pollen grains, spores, freshwater algae and marine palynomorph recognized in the studied facies.

\section{ALGAE}

Algae cf. Balmeela sp. (Figura 6G)

\section{SPORES}

Deltoidospora adriennis Potonié \& Gelletich, 1933 (Figura 5A)

Laevigatosporites tibuensis Jaramillo \& Dilcher, 2001 (Figura 5B)

Verrucatosporites usmensis Germeraad et al., 1968 (Figura 5D)

\section{GYMNOSPERMAE}

?Araucariacites sp. (Figura 5C)

\section{ANGIOSPERMAE}

Bombacacidites clarus Sah,1967 (Figura 6F)

Brevitricolporado sp. (Figura 6C)

Callimothallus sp. (Figura 6I)

Ilexpollenites sp. (Figura 50)

Lanagiopollis crassa Van der Hammen \& Wymstra, 1964 (Figura 6B)

Mauritiidites franciscoi (van der Hammen, 1956) van Hoekenklinkenberg, 1964 (Figura 6A)

Monoporopollenites annulatus (van der Hammen, 1954) Jaramillo \& Dilcher, 2001 (Figura 5F)

Multiareolites formosus Germeraad et al., 1968 (Figura 6D, E)

?Parsonsidites sp. (Figura 5J)

Psilatricolpites divisus Regali et al., 1974 (Figura 5I)

Psilatricolpites sp1. (Figura 5G)

Psilatricolpites sp2. (Figura 5H)

Retimonocolpites cf. R. maximus (Figura 5L)

Retimonocolpites sp. (Figura 5E)

Tetracolporopollenites transversalis (Dueñas, 1980) Jaramillo \& Dilcher, 2001 (Figura 5N)

Tricolporopollenites edmundii (Potonié, 1931) Thomson \& Plug, 1953 (Figura 5K)

Zonocostites sp. (Figura 5M)

\section{MARINE PALYNOMORPH}

Palinoforaminífero (Figura 6-H) 